\title{
Development, validation and implementation of radio-HPLC methods for the P2X7-receptor-targeted $\left[{ }^{11} \mathrm{C}\right] \mathrm{GSK} 1482160$ radiopharmaceutical
}

Carmen L. Wissmann, Min Wang, Mingzhang Gao, Qi-Huang Zheng, Mark A. Green*

Department of Radiology and Imaging Sciences, Indiana University School of Medicine, Indianapolis, Indiana, US.

*Address for Correspondence: $\quad$ Mark A. Green, Ph.D.

Professor of Radiology and Imaging Sciences

Indiana University School of Medicine

Department of Radiology and Imaging Sciences

950 West Walnut Street; R2-E124

Indianapolis, IN 46202 USA

E-mail: magreen@iu.edu

Phone: $317-278-9844$

Fax: 317-274-1067

Key Words: $\left[{ }^{11}\right.$ C]GSK1482160; radio-analytical HPLC method; P2X7 receptor; inflammation.

Abbreviated title: Radio-HPLC Methods for $\left[{ }^{11}\right.$ C]GSK1482160

This is the author's manuscript of the article published in final edited form as:

Wissmann, C. L., Wang, M., Gao, M., Zheng, Q.-H., \& Green, M. A. (2018). Development, validation and implementation of radio-HPLC methods for the P2X7-receptor-targeted [11C]GSK1482160 radiopharmaceutical. Applied Radiation and Isotopes, 142, 8-11. https://doi.org/10.1016/j.apradiso.2018.09.007 


\section{Abstract}

A radio-analytical RP-HPLC method was developed and validated to support production of the P2X7receptor-targeted $\left[{ }^{11} \mathrm{C}\right]$ GSK1482160 radiopharmaceutical. Method validation included characterization of retention times, peak shapes, linearity, accuracy, precision, selectivity, limits of detection and quantitation (UV signal), radiochemical stability, as well as analytical method range and robustness. The validated radio-HPLC method is suitable for the definition of $\left[{ }^{11} \mathrm{C}\right] \mathrm{GSK} 1482160$ radiochemical identity, radiochemical purity as well as molar activity, and is being employed in support of human studies with $\left[{ }^{11} \mathrm{C}\right] \mathrm{GSK} 1482160$.

\section{Introduction}

The P2X7 receptor is expressed on cells of hematopoietic origin, such as activated macrophages, monocytes, and microglia (Adinolfi et al., 2018; Barlett et al., 2014; Collo et al., 1997; Di Virgilio et al., 2017; Domercq et al., 2013; Sanz et al., 2009; Skaper et al., 2010; Volonte et al., 2012), and is rapidly up-regulated by inflammatory stimuli. Thus, the P2X7 receptor appears attractive as a possible molecular target for development of diagnostic imaging agents to evaluate and monitor tissue inflammation.

GSK1482160 is a negative allosteric modulator of P2X7 function (Abdi et al., 2010; Ali et al., 2012) with documented bioavailability, pharmacokinetics, pharmacodynamics, safety, and tolerability after oral administration to humans (Ali et al., 2012). The high affinity of GSK1482160 $\left(K_{d}=1.1 \mathrm{nM}\right)$ for the human P2X7 receptor (Territo et al., 2017), coupled with its established human pharmacology (Ali et al., 2012), make [ $\left.{ }^{11} \mathrm{C}\right] \mathrm{GSK} 1482160$ (Gao et al. 2015; Territo et al., 2017), (Figure 1), an attractive candidate radiopharmaceutical for assessing whether $\mathrm{P} 2 \mathrm{X} 7$ receptor expression can serve as a marker for PET detection of regional inflammation. 
We report here the development and validation of a reversed-phase high performance liquid chromatography (RP-HPLC) radio-analytical method suitable for pre-release quality control testing of $\left[{ }^{11} \mathrm{C}\right]$ GSK1482160 radiopharmaceutical intended for administration to human research subjects.

\section{Materials and Methods}

$\left[{ }^{11} \mathrm{C}\right]$ GSK1482160 was synthesized following the methods described previously (Gao et al. 2015). A Waters 1524 HPLC Binary System, equipped with both a Waters 2487 UV Detector and a Carroll \& Ramsey single channel high sensitivity radiation detector, was used to provide a qualitative and quantitative determination of $\left[{ }^{11} \mathrm{C}\right] \mathrm{GSK} 1482160$ in radiopharmaceutical samples. The validated radioHPLC method employed a C18 Prodigy column, $5 \mu \mathrm{m}$ ODS - 3 V $100 \AA$ ( $250 \times 4.6 \mathrm{~mm})$, eluted isocratically with mobile phase, containing $35.6 \%$ acetonitrile : $64.4 \% 20 \mathrm{mM}$ aqueous phosphoric acid at a flow rate of $1.80 \mathrm{~mL} / \mathrm{min}$ (20 $\mu \mathrm{L}$ HPLC sample injections). Non-radioactive GSK1482160 and desmethyl-GSK1482160 precursor (Gao et al., 2015) were detected and analyzed based on their UV absorbance at $275 \mathrm{~nm}$ (the measured $\lambda_{\max }$ value of both GSK1482160 and desmethyl-GSK1482160), while $\left[{ }^{11} \mathrm{C}\right]$ GSK 1482160 and radiochemical impurities were detected with the downstream scintillation detector. Desmethyl-GSK1482160 precursor and GSK1482160 reference standard solutions were prepared at various concentration levels ranging from $0.3 \mathrm{nmol} / \mathrm{mL}$ to $15.0 \mathrm{nmol} / \mathrm{mL}$ (in the expected concentration range of the radiopharmaceutical sample synthesized) to demonstrate analytical HPLC method performance.

Reversed phase high performance liquid chromatography (RP-HPLC) radio-analytical method validation included characterization of retention times $\left(t_{R}\right)$, peak shapes, linearity, accuracy, precisionrepeatability, selectivity, system suitability, chemical and radiochemical stability, as well as limits of detection and quantitation (UV signal) for both desmethyl-GSK1482160 precursor and GSK1482160. Data obtained from linearity, accuracy and precision studies was used to assess method range and robustness. Molar activity was calculated from the quantity of radioactivity injected and the 
GSK1482160 carrier mass quantified with the UV detector. The method established with the nonradioactive standards was validated in three production runs of $\left[{ }^{11} \mathrm{C}\right] \mathrm{GSK} 1482160$ radiopharmaceutical product, demonstrating tracer identity, chemical and radiochemical purity and radiochemical stability.

In addition, we report the findings from our subsequent implementation of the method in support of PET studies with $\left[{ }^{11} \mathrm{C}\right] \mathrm{GSK} 1482160$ in ten normal human volunteers.

\section{Results and Discussion}

A robust reverse phase $\left(C_{18}\right)$ HPLC method for $\left[{ }^{11} \mathrm{C}\right] \mathrm{GSK} 1482160$ was developed and validated, employing isocratic elution with a mobile phase of $35.6 \%$ acetonitrile : $64.4 \% 20 \mathrm{mM}$ aqueous phosphoric acid. In accordance with USP <1225> Validation of compendial procedures (2018), typical analytical performance characteristics along with methods by which it may be measured were assessed to demonstrate the suitability of the HPLC analytical procedure. In characterizing the suitability of the HPLC method, we took into account the synthetic route to the $\left[{ }^{11} \mathrm{C}\right] \mathrm{GSK} 1482160$ radiopharmaceutical, the suitability of the chromatographic conditions, and the HPLC column along with the UV detector signal responses.

USP < 1226> Verification of compendial procedures (2018) does not provide specific acceptance criteria for the performance characteristics of the radio-analytical HPLC methods due to the fact that the verification and validation requirements are based on the complexity of the procedure and the materials to which the procedure is applied to. Therefore, our acceptance criteria for the performance characteristics of the radio-HPLC analytical method was based on laboratory studies, demonstrating the identity, strength, quality and purity of $\left[{ }^{11} \mathrm{C}\right] \mathrm{GSK} 1482160$ radiopharmaceutical produced. Our implemented specifications for the product quality include: radiochemical purity $\geq 95 \%$; desmethylGSK1482160 present at $\leq 5 \%$ of the UV-detected GSK1482160 mass; radiochemical identity established by HPLC retention time within $10 \%$ of the reference standard. These specifications are 
consistent with former USP Monographs for other ${ }^{11} \mathrm{C}$-labeled PET radiopharmaceuticals(e.g., $\left[{ }^{11} \mathrm{C}\right]$ raclopride). Our specification for molar activity was $\geq 0.50 \mathrm{mCi} / \mathrm{nmol}(\geq 18.5 \mathrm{MBq} / \mathrm{nmol})$ at expiration. At this molar activity limit, the administered mass of GSK1482160 will remain below 20- $\mu \mathrm{g}$, even at the expected maximum administered $\left[{ }^{11} \mathrm{C}\right] \mathrm{GSK} 1482160$ dose of $30 \mathrm{mCi}(1.1 \mathrm{GBq})$. This maximal mass dose of GSK1482160 can be regarded as pharmacologically benign, based on the reported clinical trial oral dosing of GSK1482160, the associated blood levels of GSK1482160, and the reported minimum anticipated biological effect level of $4 \mathrm{ng} / \mathrm{mL}$ blood (Ali et al, 2012).

As such, system suitability testing was performed to verify that the accuracy and precision of the HPLC system was adequate for analysis. System parameters such as: resolution (R), tailing factor (T), plate count $(\mathrm{N})$ and relative standard deviation (RSD) for ten replicate standard injections of the solution containing both analytes (desmethyl-GSK1482160 and GSK1482160) at 100\% of the targeted concentration (target/nominal concentration of $10.0 \mathrm{nmol} / \mathrm{mL}$ ) were determined. Selectivity (specificity) was demonstrated for both analyte peaks. Desmethyl-GSK1482160 precursor and GSK1482160 peaks were found to be well separated, with retention times $\left(t_{R}\right)$ of 5.6 and 7.2 minutes, respectively (Figure 2), and without interference from other chemical entities. The resolution (R) between the two components was $\mathrm{R}>5$. The tailing factor $(T)$ for both desmethyl-GSK1482160 and GSK1482160 standard was $1<T<2$. The plate count or theoretical plates $(\mathrm{N})$ were $\mathrm{N}>6000$.

Standard samples solutions were prepared at five concentration levels (in the expected radiopharmaceutical sample concentration range) with triplicate sample preparation for each concentration, in order to establish calibration curves for both components, desmethyl-GSK1482160 and GSK1482160 respectively (see Appendix A. Supplementary material).

The minimum level at which both components can be reliably detected, as expressed by Limit of Detection (LOD), was calculated based on the signal-to-noise ratio. Measured signals of known low concentration standard solutions were compared to saline blank sample solutions, and the minimum concentration at which the analytes could be reliably detected was established. A signal-to-noise ratio 
of 7:1 was considered to be acceptable for establishing LOD (the lowest standard concentration for six consecutive standard injections, with an RSD $<10 \%$, was considered to provide reliable detection). The Limits of Detection (LOD) were $0.30 \mathrm{nmol} / \mathrm{mL}$ for both the desmethyl-GSK1482160 precursor and GSK1482160. A signal-to-noise ratio of 13:1 was considered acceptable for establishing the Limits of Quantitation (LOQ). The Limit of Quantitation was established according to USP <1225> Validation of Compendial Procedures (2018), as the lowest sample concentration that gives a signal-to-noise ratio of at least 10:1 (the minimum concentration at which the sample can be reliably quantified), or a peak height at least ten times the baseline noise level. Based on experimental data (Appendix A. Supplementary Material), the Limits of Quantitation (LOQ) were $0.60 \mathrm{nmol} / \mathrm{mL}$ for both components, desmethyl-GSK1482160 precursor and GSK1482160 respectively.

Method accuracy was demonstrated for desmethyl-GSK1482160 and GSK1482160 by preparing three replicate standard sample solutions at three concentration levels over the range of $50 \%$ to $150 \%$ of the nominal sample concentration (of $10.0 \mathrm{nmol} / \mathrm{mL}$ ). The acceptance criteria as represented by the Relative Standard Deviation (RSD) for the three replicate samples was established as less than $5 \%$ and the mean sample recovery was deemed acceptable within the range of $90 \%$ to $110 \%$ of the sample concentration theoretical value. The RSD for both components was RSD $<5 \%$ and the $\%$ Average Sample Recovery was within the acceptable range (of $90 \%-110 \%$ of theoretical value) for both components (experimental data is included in the Appendix A. Supplementary material).

The precision-repeatability was demonstrated by performing ten replicate HPLC injections of a standard sample solution at the nominal concentration (of $10 \mathrm{nmol} / \mathrm{mL}$ ) and according to the HPLC method procedure. The precision-repeatability acceptance criteria was established by the Relative Standard Deviation, as RSD $<5.0 \%$ for the retention times, peak heights and peak area responses for both components (see Appendix A. Supplementary material).

Linearity was demonstrated in the sample concentration range of $1 \mathrm{nmol} / \mathrm{mL}$ to $15 \mathrm{nmol} / \mathrm{mL}$ (for both desmethyl-GSK1482160 and GSK1482160). The linearity acceptance criteria was established by the 
correlation coefficient $\left(R^{2}\right)$, as $R^{2} \geq 0.980$ and the $y$-intercept, as $y$-intercept $<2 \%$ of the target concentration area response. The correlation coefficient $\left(R^{2}\right)$ calculated at five standard concentration levels, was $\mathrm{R}^{2}>0.999$, while the $\mathrm{y}$-intercept $\%$ of target concentration response was $<2 \%$ for both components (see Appendix A. Supplementary material).

Data obtained during linearity, accuracy and precision determinations were used to assess the range of the radio-HPLC analytical method. The analytical method has a suitable level of precision, accuracy and linearity in the sample concentration range of $1 \mathrm{nmol} / \mathrm{mL}$ to $15 \mathrm{nmol} / \mathrm{mL}$. The HPLC analytical method proved to be robust and remained unaffected by small deliberate variations in the procedural parameters, or small changes in the chromatographic conditions (e.g., unchanged across various batches of the HPLC columns, different HPLC systems, different analysts, minor changes in the ambient temperature of $\pm 2^{\circ} \mathrm{C}$, minor mobile phase $\mathrm{pH}$ variations of \pm 0.2 , minor flow rate variations of $\pm 0.1 \mathrm{~mL} / \mathrm{min})$.

In addition, radiotracer identity for the $\left[{ }^{11} \mathrm{C}\right] \mathrm{GSK} 1482160$ radiopharmaceutical was established based on demonstrating an HPLC retention time identical to the non-radioactive GSK1482160 standard (Figure 2, Figure 3). The $\left[{ }^{11} \mathrm{C}\right] \mathrm{GSK} 1482160$, with a retention time of 7.2 minutes, was well resolved from an unidentified minor radiochemical impurity $(<5.0 \%)$ with the retention time of 5.2 minutes (Figure 3). We have been unable to establish the chemical identity of this radiochemical impurity, as it generates no corresponding UV signal on the UV detector.

The stability of the $\left[{ }^{11} \mathrm{C}\right]$ GSK 1482160 product was demonstrated by repeating the radio-HPLC analysis at, or beyond, the radiopharmaceutical's expiration time (set as no more than one hour from the terminal sterilizing filtration). There was no evidence of the degradation of the $\left[{ }^{11} \mathrm{C}\right] \mathrm{GSK} 1482160$ product at room temperature, with the radiochemical purity always exceeding $95 \%$ at the expiration time for the validation batches (Table 1). The final formulation of the radiopharmaceutical drug product was isotonic sterile saline $(0.9 \%$ sodium chloride) containing $\sim 5 \%$ ethanol.

Radio-HPLC method validation involving the analysis of the $\left[{ }^{11} \mathrm{C}\right] \mathrm{GSK} 1482160$ from three production 
runs consistently showed the the desmethyl-GSK1482160 precursor to be absent in the final product (Figure 4).

The undesired ${ }^{11} \mathrm{C}$ - isomeric side-product, which arises in small amounts by competitive ${ }^{11} \mathrm{C}$ methylation at the side chain amide $\mathrm{N}$ position of the desmethyl-GSK1482160 precursor (Figure 1), was always effectively removed in the semi-preparative HPLC separation of the production process that precedes final $\left[{ }^{11} \mathrm{C}\right] \mathrm{GSK} 1482160$ formulation.

Radio-HPLC of the isomeric impurity produced (Figure 1) as a minor side-product and isolated as a separate fraction after collecting the $\left[{ }^{11} \mathrm{C}\right] \mathrm{GSK} 1482160$ fraction in semi-preparative HPLC shows a small quantity of $\left[{ }^{11} \mathrm{C}\right] \mathrm{GSK} 1482160$ at $t_{R}=7.2$ minutes, in addition to the isomeric side-product with $t_{R}=$ 7.9 minutes (Figure 5). Using the validated analytical HPLC method for $\left[{ }^{11} \mathrm{C}\right] \mathrm{GSK} 1482160$ analysis, we determined that the ${ }^{11} \mathrm{C}$-side-product $\left(t_{R}=7.9\right.$ minutes; Figure 5$)$ is well separated from the $\left[{ }^{11} \mathrm{C}\right] \mathrm{GSK} 1482160$ product $\left(t_{R}=7.2\right.$ minutes; Figure 3$)$. The final formulated $\left[{ }^{11} \mathrm{C}\right] \mathrm{GSK} 1482160$ radiopharmaceutical product never showed evidence of radiochemical contamination by the undesired alkylation isomer.

Repeated chromatographic analyses show no evidence of the GSK1482160 reference standard degradation over one year, as well as no evidence of $\left[{ }^{11} \mathrm{C}\right] \mathrm{GSK} 1482160$ degradation over the one-hour period prior to its labeled expiration.

This radio-HPLC method has been fully implemented as part of the quality control procedures for the $\left[{ }^{11} \mathrm{C}\right]$ GSK1482160 synthesized for use in PET imaging with human subjects. In production runs for the first ten subjects, $\left[{ }^{11} \mathrm{C}\right]$ GSK1482160 radiochemical purity averaged $96.25 \pm 1.25 \%$, with a molar activity average of $0.51 \pm 0.1 \mathrm{mCi} / \mathrm{nmol}(18.9 \pm 3.7 \mathrm{MBq} / \mathrm{nmol})$ at the labeled dose expiration time (Table 2). At the time of administration, molar activity averaged $1.03 \pm 0.28 \mathrm{mCi} / \mathrm{nmol}(38.1 \pm 10.4 \mathrm{MBq} / \mathrm{nmol})$, with doses averaging $26 \pm 2 \mathrm{mCi}(962 \pm 74 \mathrm{MBq})$. 


\section{Conclusions}

A reversed phase high performance liquid chromatography (RP-HPLC) radio-analytical method was developed, and its performance validated to meet USP guidelines for linearity, accuracy, precision, selectivity, limit of detection, limit of quantitation (UV signal), range, and robustness. The analytical method is robust and unaffected by small changes in chromatographic conditions. The performance of this radio-analytical method is suitable for pre-release assessment of [ $\left.{ }^{11} \mathrm{C}\right] \mathrm{GSK} 1482160$ radiopharmaceutical, defining product radiochemical purity, molar activity, as well as the absence of contamination by the desmethyl-GSK1482160 precursor. This radio-HPLC method supports delivery of the $\left[{ }^{11} \mathrm{C}\right] \mathrm{GSK} 1482160$ radiopharmaceutical in accordance with the requirements for identity, strength, quality and purity outlined in USP <823> Positron emission tomography drugs for compounding, investigational, and research uses (2018). 


\section{Acknowledgements}

This work was supported by Indiana University School of Medicine, Department of Radiology and Imaging Sciences and the Renal Imaging Technology Development Program of the IUPUI Research Center for Quantitative Renal Imaging.

\section{Appendix A. Supplementary material}

Supplementary data associated with this article can be found in the online version at:

\section{References}

Abdi, M., Beswick, P., Billinton, A., Chambers, L., Charlton, A., Collins, S., Collis, K., Dean, D., Fonfria, E., Gleave, R., Lejeune, C., Livermore, D., Medhurst, S., Michel, A., Moses, A., Page, L., Patel, S., Roman, S., Senger, S., Slingsby, B., Steadman, J., Stevens, A. and Walter, D. 2010. Discovery and structure-activity relationships of a series of pyroglutamic acid amide antagonists of the P2X7 receptor. Bioorg. Med. Chem. Lett. 20, 5080-5084.

Adinolfi, E., Giuliani, A., De Marchi, E., Pegoraro, A., Orioli, E. and Di Virgilio, F. 2018. The P2X7 receptor: A main player in inflammation. Biochem. Pharmacol. 151, 234-244.

Ali, Z., Laurijssens, B., Ostenfeld, T., McHugh, S., Stylianou, A., Scott-Stevens, P., Hosking, L., Dewit, O., Richardson, J. and Chen, C. 2012. Pharmacokinetic and pharmacodynamic profiling of a P2X7 receptor allosteric modulator GSK1482160 in healthy human subjects. Br. J. Clin. Pharmacol. 75, 197207. 
Bartlett, R., Stokes, L. and Sluyter, R. 2014. The P2X7 receptor channel: recent developments and the use of P2X7 antagonists in models of disease. Pharmacol. Rev. 66, 638-675.

Collo, G., Neidhart, S., Kawashima, E., Kosco-Vilbois, M., North, R. and Buell, G. 1997. Tissue distribution of the P2X7 receptor. Neuropharmacology 36, 1277-1283.

Di Virgilio, F., Dal Ben, D., Sarti, A., Giuliani, A. and Falzoni, S. 2017. The P2X7 receptor in infection and inflammation. Immunity 47, 15-31.

Domercq, M., Vazquez-Villoldo, N. and Matute, C. 2013. Neurotransmitter signaling in the pathophysiology of microglia. Front. Cell. Neurosci. 7, 1-17.

Gao, M., Wang, M., Green, M., Hutchins, G. and Zheng, Q. 2015. Synthesis of $\left[{ }^{11} \mathrm{C}\right]$ GSK1482160 as a new PET agent for targeting P2X7 receptor. Bioorg. Med. Chem. Lett. 25, 1965-1970.

Sanz, J., Chiozzi, P., Ferrari, D., Colaianna, M., Idzko, M., Falzoni, S., Fellin, R., Trabace, L. and Di Virgilio, F. 2009. Activation of microglia by amyloid (beta) requires P2X7 receptor expression. J. Immunol. 182, 4378-4385.

Skaper, S., Debetto, P. and Giusti, P. 2010. The P2X7 purinergic receptor: from physiology to neurological disorders. FASEB J. 24, 337-345.

Territo, P., Meyer, J., Peters, J., Riley, A., McCarthy, B., Gao, M., Wang, M., Green, M., Zheng, Q. and Hutchins, G. 2017. Characterization of ${ }^{11} \mathrm{C}$-GSK1482160 for targeting the P2X7 receptor as a biomarker for neuroinflammation. J. Nucl. Med. 58, 458-465. 
USP. 2018. Positron emission tomography drugs for compounding, investigational, and research uses <823>. In: USP41-NF36. Rockville, MD. 823, 6629.

USP. 2018. Validation of compendial procedures <1225>. In: USP41-NF36, Rockville, MD. 1225, 7665.

USP. 2018. Verification of compendial procedures <1226>. In: USP41-NF36. Rockville, MD. 1226, 7671.

Volonte, C., Apolloni, S., D. Skaper, S. and Burnstock, G. 2012. P2X7 receptors: channels, pores and more. CNS Neurol. Disord.: Drug Targets. 11, 705-721.

\section{Figures}

Figure 1. Synthetic route to the $\left[{ }^{11} \mathrm{C}\right] \mathrm{GSK} 1482160$ radiopharmaceutical (Gao et al., 2015).

Figure 2. HPLC-UV: Example of the separation of desmethyl-GSK1482160 precursor and GSK1482160 ( $t_{R}$ Desmethyl-GSK1482160 $=5.6$ minutes, $t_{R}$ GSK1482160 $=7.2$ minutes) .

Figure 3. Radio-HPLC results for a typical $\left[{ }^{11} \mathrm{C}\right] \mathrm{GSK} 1482160$ radiopharmaceutical preparation $\left(t_{R}\right.$ Radiochemical impurity $=5.2$ minutes, $t_{R}\left[{ }^{11} \mathrm{C}\right] \mathrm{GSK} 1482160=7.2$ minutes $)$.

Figure 4. HPLC-UV results for a typical $\left[{ }^{11} \mathrm{C}\right] \mathrm{GSK} 1482160$ final product sample $\left(t_{R}\right.$ GSK1482160 $=7.1$ 
minutes, sample concentration $=10 \mathrm{nmol} / \mathrm{mL}$ ).

Figure 5. Radio-HPLC of the isomeric impurity fraction $\left(t_{R}\left[{ }^{11} \mathrm{C}\right] \mathrm{GSK} 1482160=7.2\right.$ minutes, $t_{R}$ Isomeric impurity $=7.9$ minutes).

Table 1. Characteristics of three $\left[{ }^{11} \mathrm{C}\right] \mathrm{GSK} 1482160$ validation batches analyzed using the validated radio-HPLC analytical method.

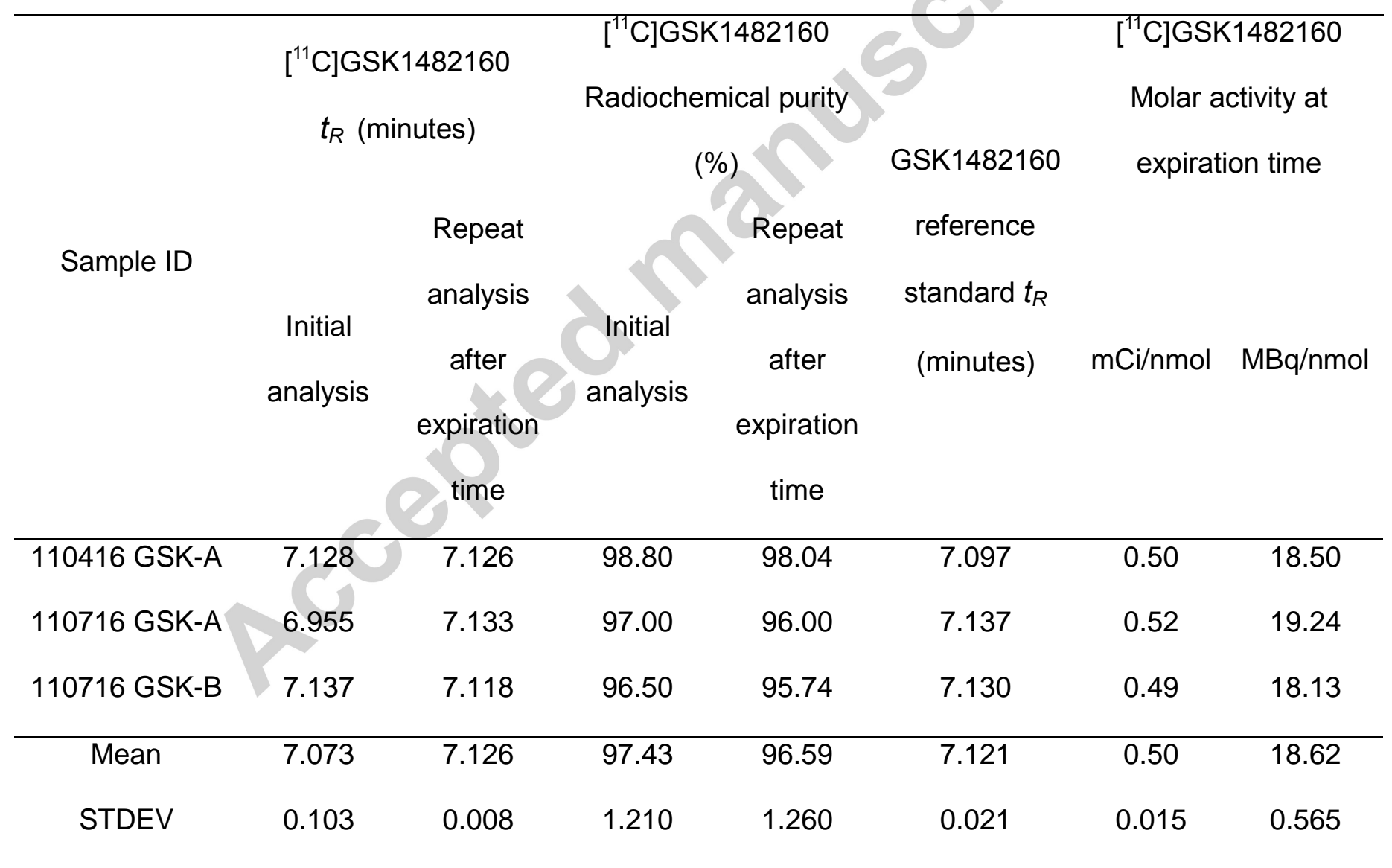


Table 2. $\left[{ }^{11} \mathrm{C}\right] \mathrm{GSK} 1482160$ study in ten volunteers used for PET imaging.

\begin{tabular}{|c|c|c|c|c|c|c|}
\hline Sample ID & $\begin{array}{l}\text { Radiochemi } \\
\text { cal purity } \\
(\%)\end{array}$ & $\begin{array}{l}\text { GSK mass } \\
\text { (nmol/mL) }\end{array}$ & $\begin{array}{c}\text { Sample } \\
\text { volume }(\mathrm{mL})\end{array}$ & $\begin{array}{l}\text { Activity at } \\
\text { EOS (mCi) }\end{array}$ & $\begin{array}{l}\text { Activity at } \\
\text { expiration } \\
(\mathrm{mCi} / \mathrm{mL})\end{array}$ & $\begin{array}{c}\text { Molar } \\
\text { activity at } \\
\text { expiration } \\
(\mathrm{mCi} / \mathrm{nmol})\end{array}$ \\
\hline 081817 GSK-A & 97.40 & 3.90 & 11.30 & 131.00 & 1.95 & 0.50 \\
\hline 083017 GSK-A & 96.80 & 3.56 & 10.90 & 125.50 & 1.81 & 0.51 \\
\hline 091517 GSK-A & 95.30 & 3.70 & 10.80 & 167.30 & 1.8 & 0.50 \\
\hline 092817 GSK-A & 96.40 & 5.25 & 11.20 & 175.70 & 2.64 & 0.50 \\
\hline 100217 GSK-A & 97.40 & 4.47 & 10.60 & 121.80 & 2.30 & 0.51 \\
\hline 100317 GSK-A & 96.30 & 5.36 & 11.20 & 187.60 & 2.73 & 0.51 \\
\hline 102717 GSK-A & 95.00 & 4.45 & 10.30 & 241.00 & 2.28 & 0.51 \\
\hline 110917 GSK-A & 97.20 & 4.36 & 10.30 & 159.00 & 2.27 & 0.52 \\
\hline 111017 GSK-A & 97.50 & 4.30 & 10.00 & 121.90 & 2.20 & 0.51 \\
\hline 112017 GSK-A & 96.60 & 10.00 & 10.50 & 214.00 & 5.18 & 0.52 \\
\hline Mean & 96.59 & 4.93 & 10.71 & 164.48 & 2.52 & 0.51 \\
\hline STDEV & 0.87 & 1.87 & 0.44 & 41.21 & 0.98 & 0.01 \\
\hline
\end{tabular}




\section{Highlights}

- A radio-analytical method was validated for the $\left[{ }^{11} \mathrm{C}\right] \mathrm{GSK} 1482160$ radiopharmaceutical.

- The method proved to be robust and unaffected by small changes in the chromatographic conditions.

- The $\left[{ }^{11} \mathrm{C}\right]$ GSK1482160 radiopharmaceutical exhibits high radiochemical stability.

- $\left[{ }^{11} \mathrm{C}\right]$ GSK1482160 radiopharmaceutical can be delivered in accordance with USP <823> requirements.

- The P2X7-receptor-targeted $\left[{ }^{11} \mathrm{C}\right]$ GSK1482160 meets release criteria for human use.

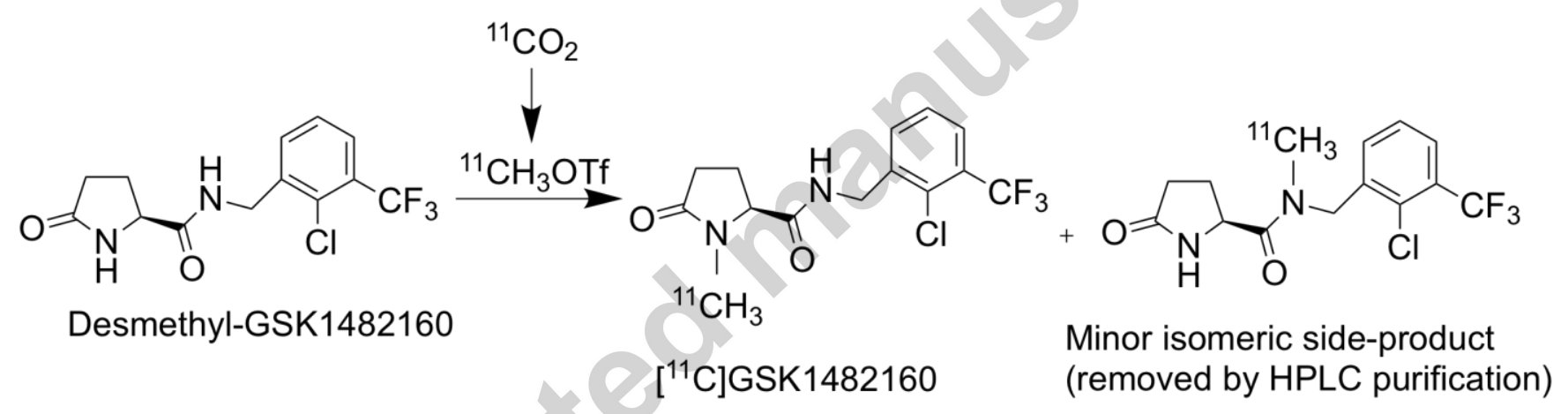



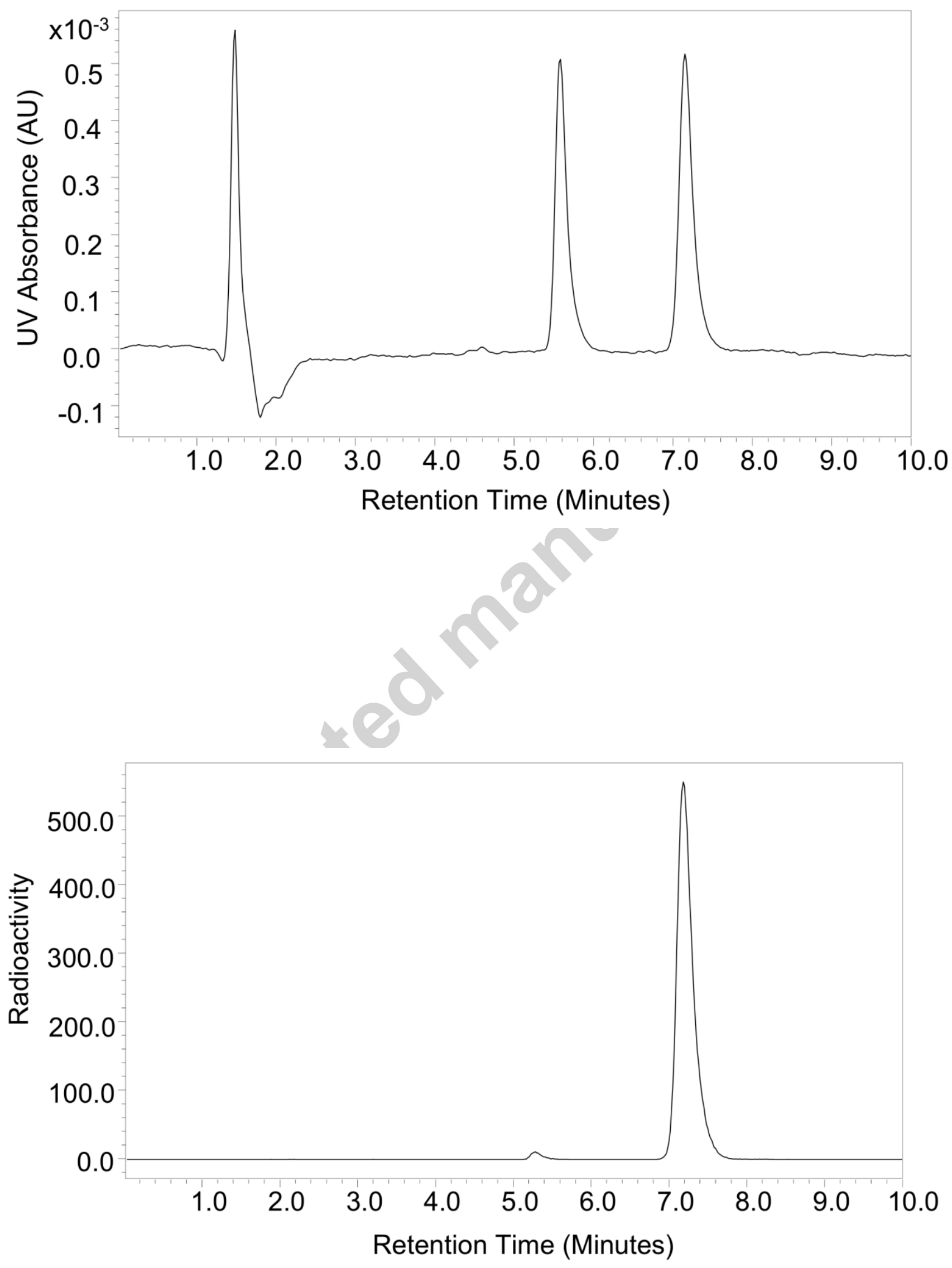


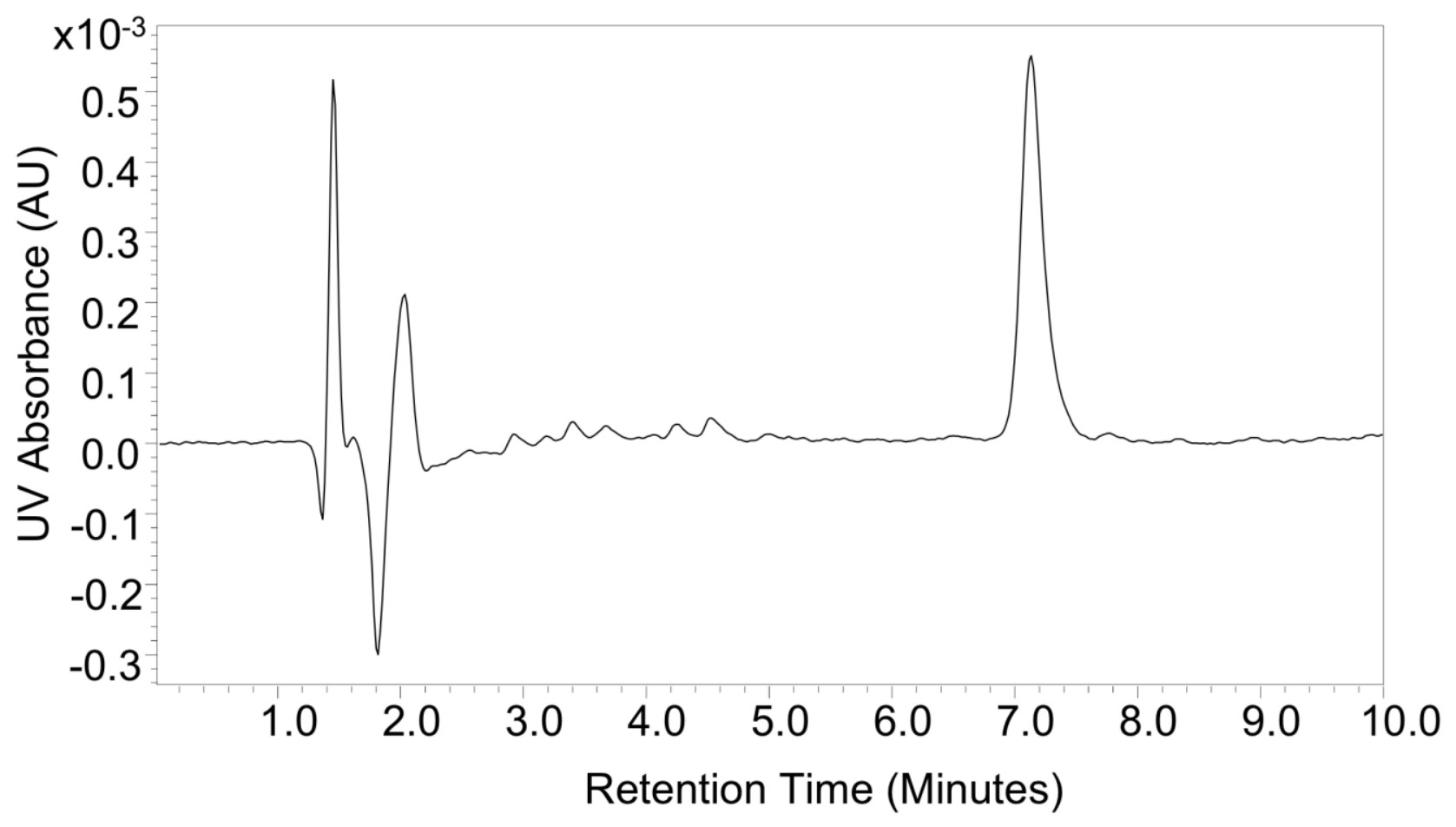




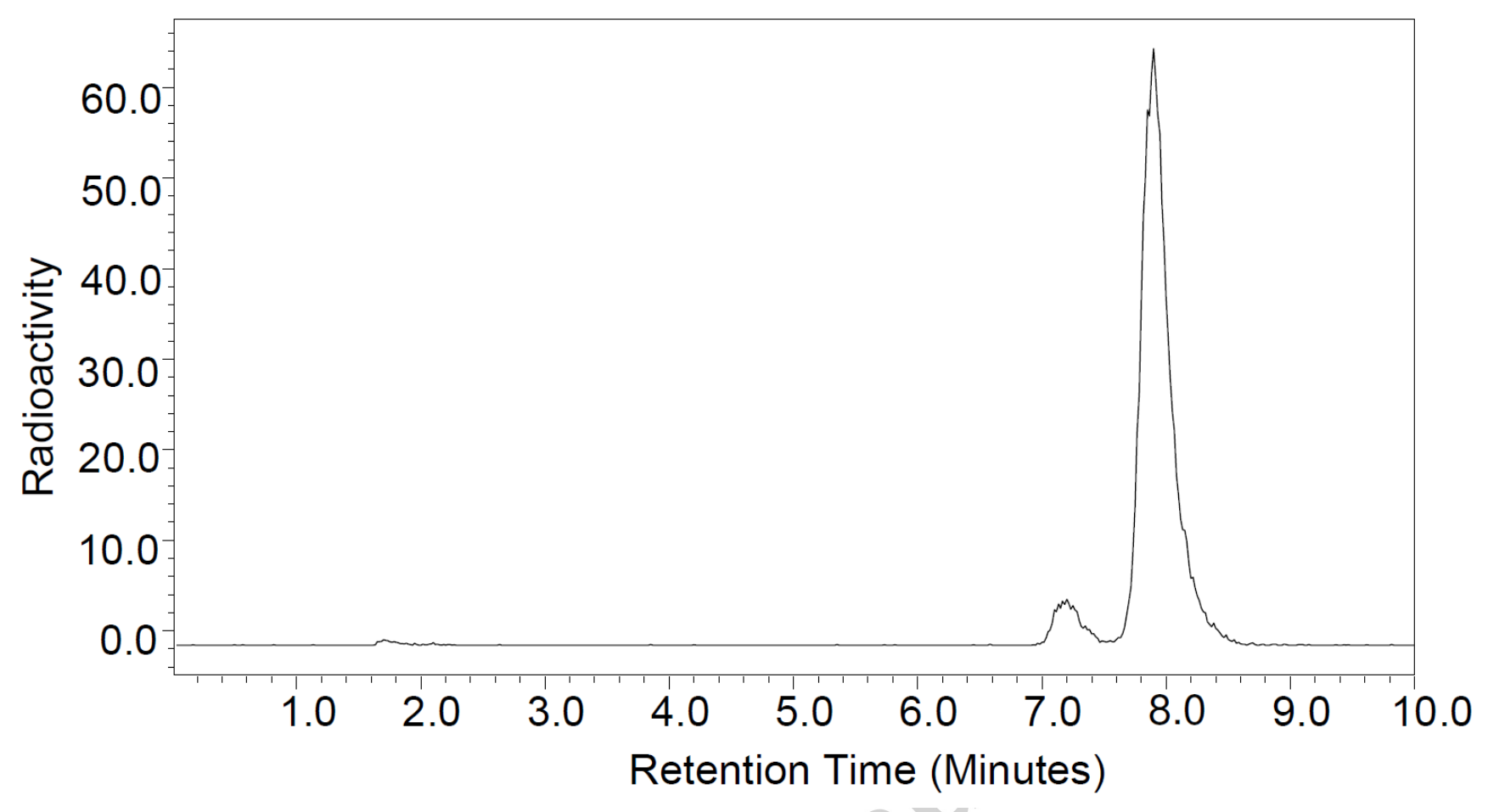

